\title{
DELEUZE GÓTICO
}

\author{
Gothic Deleuze
}

\author{
Martin González Fernández \\ Universidad de Santiago de Compostela
}

\section{Resumen}

Este artículo trata de examinar las raíces medievales del pensamiento de Gilles Deleuze, uno de los padres de la posmodernidad en filosofía; concretamente sus débitos con Juan Duns Escoto. Nos centramos en siete categorías filosóficas: univocidad del ser, distinción formal, potencia, haecceitas, materia, coexistencia de formas, modo intrínseco e intensidad.

\section{Palabras clave}

Juan Duns Escoto; Gilles Deleuze; ontología; filosofía medieval; postmodernidad

\begin{abstract}
This article traces the medieval roots of the thought of Gilles Deleuze, one of the founders of postmodern philosophy, specifically, his debts to John Duns Scotus. It focuses on seven philosophical categories: univocity of being, formal distinction, potency, haecceitas, matter, coexistence of forms and modus intrinsicus or intensity.
\end{abstract}

\section{Keywords}

John Duns Scotus; Gilles Deleuze; ontology; medieval philosophy; postmodernity

\section{Blanco sobre negro}

Calificamos aquí de gótica a la escolástica tardía medieval ${ }^{1}$. Y aplicamos a Gilles Deleuze (1925-1995), autor post-estructuralista y post-moderno, paradójica y provocadoramente, este mismo apelativo, por creer que dicha filosofía ha tenido un papel relevante en la hermenéutica filosófica y en el propio discurso de este autor contemporáneo nuestro. Siempre nos llamó la atención esta deuda, por lo general reconocida por

\footnotetext{
${ }^{1}$ A Jorge Ayala Martínez, a quien tanto debe el medievalismo ibérico contemporáneo.
} 
el autor, todo hay que decirlo, y no somos los primeros en apreciarla y escribir sobre ella ${ }^{2}$. Quien se acerque a Deleuze por vez primera observará que su obra está sedimentada por capas, en las que juega un lugar importante F. Nietzsche, sobre el que escribió su primer libro de impacto, en 1962, y Spinoza, sobre el que nos ha dejado tres magníficas monografías (la última, póstuma, lecciones dictadas en la Universidad de Vincennes). Pero la filosófica es apenas una de las muchas capas o pliegues de su obra, pues, experimentando con la diferencia, hay otros substractos relativos a la literatura, a la ciencia, al cine o al arte, siempre en textos por lo general muy intuitivos.

Esta es la veta que a nosotros nos interesa en el presente trabajo, el impacto de la filosofía gótica en su obra, y en concreto la huella en ella de Juan Duns Escoto. Decimos que hay paradoja porque su santoral no es precisamente el cristiano; es más, en el esquema deconstructivo del autor, está claro que la escolástica, con todo su altar y retablo de platones y aristoteles varios, cae dentro del patrón de filosofía que él critica de modo inteligente, y abiertamente: la filosofía de la representación, o, con el tiempo, el logofalo-etno-euro-centrismo. No borra las huellas a la entrada de su madriguera gótica, y esto, no sólo lo engrandece, sino que además ayuda mucho al lector. El mérito, si cabe, es mayor si tenemos en cuentra que la cartografía deleuziana gira cara a un materialismo de corte espinoziano, muy lejos de cualquier modalidad de teología o filosofía cristiana. Ambos se hallan, en este sentido, por lo tanto, en las antípodas.

\footnotetext{
${ }^{2}$ Hemos localizado, al menos, un trabajo precedente: Ríos, E., Andrés, E., «Duns Escoto en Deleuze: Univocidad y distinción formal», En Parte Rei. Revista de filosofía, 65 (2009), pp. 1-10. Heredia Ríos está vinculado a la Universidad de Caldas (Colombia) y se basa en la lectura de Étienne Gilson del escotismo (vid. Gilson, É., Juan Duns Escoto: Introducción a sus posiciones fundamentales, Pamplona, EUNSA, 2007); o sea, en la lectura tomista; que, tal vez, no sea la más idónea para la cuestión que nos ocupa, la deuda de Deleuze con Juan Duns Escoto. (Para otras lecturas del autor medieval, puede verse, a modo de ejemplo, la monografía de Merino, J.A., Juan Duns Escoto: introducción a su pensamiento filosófico-teológico, Madrid, Biblioteca de Autores Cristianos, 2007, del mismo año que la versión española del texto de E. Gilson, y por la misma editorial.) Nos apropiamos de una cita de su interesante trabajo, y poco más, y nos alejamos del enfoque teológico general que plantea. Por lo demás, en nuestro estudio, se amplia el horizonte de la mirada filosófica. (Habría que mencionar, además, los siguientes trabajos: Correia, M., «Univocidade do ser e eterno retorno: Deleuze, Duns Escoto e a reavaliação da transcendência divina», Revista Portuguesa de Filosofia, 73/2 (2017), pp. 637-668. LaZella, A.T., «Crowned Anarchy and Nomadic Distribution: Gilles Deleuze's Transformative Appropriation of Duns Scotus», Essays in Medieval Studies, 28 (2012), pp. 23-34, y el capítulo de Nathan Widder, cap. 3, dedicado a Duns Escoto en el libro Deleuze's Philosophical Lineage, en G. Jones y J. Roffe (eds.), Edinburg, Edinburg University Press, 2009.) El fondo antiguo de nuestra centenaria Universidad, Universidad de Santiago de Compostela, es rico en comentarios y obras del Doctor Sutil y Mariano (vid., para la Universidad española en general, donde hubo cátedra de Escoto, Vázquez Janeiro, I., Enseñanza de la doctrina de Escoto en las universidades españolas. Madrid, Imprenta de los Padres Franciscanos, [fascículo], 1961).
} 


\section{Univocidad del ser}

El interés de G. Deleuze por este autor medieval aparece ya en escritos tempranos, y académicos, en concreto en su Tesis de Estado, con sus dos partes, Parte I y Parte II, principal y complementaria. La Tesis principal, o Parte I, la realizó bajo la supervisión del gran medievalista y estudioso de la filosofía del Renacimiento, Maurice de Gandillac. Se tituló: Différence et Répétition (1968) ${ }^{3}$. La Tesis secundaria, o mejor complementaria, o Parte II, la realizó bajo la dirección de otro gran especialista, en este caso, de la filosofía moderna y de Spinoza, Ferdinand Alquié. Se tituló: Spinoza et le problème de l'expression, editada en el mismo año, $1968^{4}$. No se puede quejar de sus asesores. Ya en el primer texto, hace una declaración universal y de intenciones: «Il n'y a jamais eu qu'une proposition ontologique: l'Être est univoque. Il n'y a jamais eu qu'un seule ontologie, celle de Duns Scot, qui donne à l'être une seule voix»".

Así, pues, todo lo que va a decir a continuación parte de este punto: sobre Spinoza y contra la filosofía de la representación, y en lo relativo a su cartografía- bajo el rótulo genérico de «Esquizofrenia y capitalismo», 3 títulos, Anti-Edipo, Mil Mesetas y Derrames, los dos primeros co-firmados por el psiquiatra Félix Guattari-, poniendo en su punto de mira el llamado «logo-falo-euro-etnocentrismo»; lo que lo convierte en pope del post-estructuralimo y post-modernidad, movimiento tan criticado últimamente por liberales y cartógrafos marxistas, al ser considerado algo así como una de las almas del cuerpo del capitalismo más agresivo, neoliberal post-industrial, virtual, financiero ${ }^{6}$.

Pero Deleuze le da un sesgo materialista, a través de la filosofía de Spinoza, que al autor franciscano, ciertamente, nunca se le hubiese, claro está, pasado por la cabeza.

Creemos que la filosofía de Spinoza permanece en parte ininteligible, si no se ve en ella una lucha constante contra las tres nociones de equivocidad, eminencia y analogía. Los atributos, según Spinoza, son formas de ser unívocas, que no cambian de naturaleza al cambiar de «sujeto», es decir, cuando se las predica del ser infinito y de los seres finitos, de la substancia y de los modos, de Dios y de las criaturas. En nada creemos menguar la originalidad de Spinoza reemplazándole en una pespectiva que ya era la de Duns Scoto7.

\footnotetext{
${ }^{3}$ Deleuze, G., Différence et Répétition, Paris, PUF, 1968; en español: Deleuze, G., Diferencia y repetición, Trad. M.S. Delpy y H. Beccaecece, Buenos Aires, Amorrortu, 2002.

${ }^{4}$ Deleuze, G., Spinoza et le problème de l'expression, Paris, Les Éditions de Minuit, 1968; en español: Deleuze, G., Spinoza y el problema de la expresión, trad. H. Vogel. Barcelona, Mario Muchnik, 1975.

${ }^{5}$ Deleuze, Différence et Répétition, op. cit, p. 52.

${ }^{6}$ Un buen antídoto contra el pensamiento posmoderno encarnado por Gilles Deleuze, desde la cartografía marxista, puede encontrarse en: Harvey, D., The Condition of Postmodernity. An Enquiry into the Origins of Culture Change, Oxford (GB.), Basil Blackell, 1990. (Coindimos en el diagnóstico.)

${ }^{7}$ Deleuze, Spinoza y el problema de la expresión, op. cit., pp. 42-44, el subrayado es del autor; en efecto «analogía», «equivocidad» $\mathrm{y}$ "eminencia», desde un cierto punto de vista, serían apenas formas sutiles de antropomorfismo. La admiración de Gilles Deleuze por este autor escolástico es grande: «Es sabido que Duns Scoto, en la Edad Media, había planteado este problema y le había dado una solución profunda. Duns Scoto es sin duda quien más lejos llevó la empresa de una teología positiva. Denuncia a la
} 
En esta misma tradición, la de Spinoza y Deleuze, por lo demás, encajarían un grupo de autores medievales y renacentistas: Ibn Gabirol, David de Dinant y Giordano Bruno de Nola. En sus Lecciones de Vincennes de 1980-1981 y en un registro más coloquial, lo expresaba precisamente en los términos que acabamos de reproducir:

Lo que me parece sorprendente en una ontología pura es hasta qué punto repudia la jerarquía. En efecto, no hay Uno superior al ser, el ser se dice de todo lo que es en un solo y mismo sentido. Eso es lo que me ha parecido la proposición ontológica clave. No hay unidad superior al ser y, a partir de esto, el ser se dice de todo lo que se dice, es decir de todo lo que es, de todo ente en un solo y mismo sentido. Es el mundo de la inmanencia...Hay que corregir, cada vez que digo una frase tengo ganas de corregirla...Seguramente estos filósofos de la ontología [pura, la única] nos dirán que evidentemente hace falta una jerarquía práctica. La ontología [pura, la única] no desemboca en fórmulas que serían las del nihilismo o del no-ser, fórmulas del tipo todo es igual. Y sin embargo, en cierto aspecto, todo es igual desde el punto de vista de la ontología, es decir, desde el punto de vista del ser. Todo ente efectúa su ser como está en él. Un punto es todo. El pensamiento anti-jerárquico absoluto. Es una especie de anarquía, hay una anarquía de los entes en el ser. Si ustedes quieren, es la intuición básica de la ontología: todos los seres equivalen [entre sí. Es una especie de grito: ;Sli Después de todo, desde un cierto punto de vista, desde el punto de vista del ser, la piedra, el insensato, el razonable, el animal, valen lo mismo. Cada uno es tanto como está en él. Y el ser se dice en un solo y mismo sentido de la piedra, del hombre, del loco, del razonable, etc. Es una idea muy bella. No vemos lo que les hace decir eso, pero es una idea muy bella. Envuelve incluso su crueldad, su salvajismo. Es una especie de mundo muy salvaje ${ }^{8}$.

vez la eminencia negativa de los neo-platónicos, la pseudo-afirmación [analógica y equívoca] de los tomistas. Les opone la univocidad del ser: el ser se dice en el mismo sentido de todo lo que es, infinito o finito, aunque no sea bajo la misma 'modalidad'. Pero precisamente el ser no cambia de naturaleza al cambiar de modalidad, es decir, cuando su concepto es predicado del ser infinito y de los seres finitos (ya en Scoto, la univocidad no trae consigo pues ninguna confusión de esencias) [Duns Scoto, Opus oxoniense, en Opera omnia; studio et cura commissionis scolisticae ad fidem codicum edita Praeside P. Carolo Balic, sociis Martino Bodewig (et al.) Civitas Vaticana, Typis Polyglottis Vativonis, 1950 sq., 17 Tomos: sobre la crítica de la eminencia y de la analogía, I, d3, q. 1, 2 y 3: sobre la univocidad del ser, I, d8, q. 3]. Y la univocidad del ser trae consigo ella misma la univocidad de los atributos divinos: el concepto de un atributo que puede ser elevado al infinito es común él mismo a Dios y a las criaturas. A condición de ser tomado en su razón formal o en su cosidad, pues 'la infinidad no suprime de ninguna manera la razón formal de aquello a lo que se ve agregada' [Op. ox., I, d8, q. 4 (a.2, n. 13)]. Pero, afirmándose formal y positivamente de Dios, ¿cómo los atributos infinitos o los nombres divinos no introducirían en Dios una pluralidad correspondiente a sus razones formales, a sus cosidades distintas? / Es a este problema que Escoto aplica uno de sus conceptos más originales, que viene a completar aquél de la univocidad: la idea de la distinción formal [Op. ex., d2. q. 4: D8 q. 4]» (Deleuze, Spinoza y el problema de la expresión, op. cit., pp. 56-57). Lo dejamos aquí. (Ediciones españolas de referencia del autor medieval son: Juan Duns Escoto, Obras del Doctor sutil Juan Duns Escoto. Edición bilingüe. Introducción General del Padre M. Oromí, Madrid, La Editorial Católica (BAC), 1960; y Juan Duns Escoto, Obras del doctor sutil Juan Duns Escoto: cuestiones cuodlibetales, Madrid, La Editorial Católica (BAC), 1968).

${ }^{8}$ Deleuze, G., En medio de Spinoza, Buenos Aires, Catctus, 2008 (ed. completa), p. 109 (Deleuze en diálogo con Comtese, que le interrumpe). 
Pero, como señala G. Deleuze también, no debemos entusiarmarnos demasiado, pues el recorrido de esta noción estrructural en J. Duns Escoto, no va muy lejos en la práctica, al ser, de hecho, limitado por las posiciones creacionistas del Doctor Sutil.

\section{Distinción formal}

Y una cosa lleva forzosamente a la otra. El concepto de la univocidad del ser, en efecto, está estrechamente relacionado con el de la «distinción formal»: «Es a este problema [noción de diferencia] que Escoto aplica uno de sus conceptos más originales, que viene a completar aquel de la univocidad: la idea de la distinción formal» ${ }^{9}$ (se dijo). Como indica É. Gilson, Dios continúa siendo simple, siempre y cuando sus atributos sean diversos formalmente, no numéricamente ${ }^{10}$. Sobre lo real, gravita el sentido único, lo demás son distinciones formales del ser. Deleuze lee a Spinoza en esta clave, infinitos atributos, univocidad del ser: cada atributo expresa el ser de manera diferente. He ahí la noción de «diferencia» que interesa, interna (por así decir, en estado puro, o sea, lejos de la añoranza, distorsión y placenta de la analogía, la equivocidad y la eminencia, como ya quedó apuntado). Univocidad del ser implica, como dice Michael Hardt en pasaje que cita Heredia Ríos, «una diferencia formal entre atributos, pero una comunidad ontológica real y absoluta [identidad, añadimos nosotros] entre atributos» ${ }^{11}$.

\section{Potencia absoluta y potencia ordinaria}

Sobra decir aquí, que es éste el mismo problema que contamina la noción de potencia e infinitud en este autor medieval: Dios, por su omnipotencia (noción fuerte y plena, la auténtica, de la Voluntad divina), podría desplegar una potentia absoluta, un infinito en acto, $y$, sin embargo, es fuerza que [se] contiene limitándose a ejercer una potentia ordinata (el cosmos cerrado del Génesis bíblico). Nada importa el haber superado el concepto peripatético del infinito en potencia, si, al final, renunciamos a lo alcanzado en beneficio de la ortodoxia. Es la crítica que le hará prolijamente Giordano Bruno, en su De l'infinito universo et Mondi (Londres, 1584), rechazada a su vez, como indica Miguel A. Granada Martínez, por el anotador napolitano a este texto (parcial) y el atónito Presbyter o Reverendissimus escotista del De innumerabilibus, immenso, et infigurabili (Francfort, 1591). La ecuación o identidad de potencia y acto, como señala en nota Deleuze ${ }^{12}$, al menos por lo que hace al Nous, es de uso frecuente en el neoplatonismo, tanto en el pensamiento cristiano como en el judío: es la noción del Possest que aplica a Dios el cardenal de Cusa, tan admirado por Giordano Bruno. $Y$, en ocasiones, en estas aguas turbias se han colocado (el propio Nolano es el primero en hacerlo) a figuras medievales como Ibn Gabirol o David de Dinant. No siempre se ha dado el salto al panteísmo y materialismo: aunque G. Bruno, en su caso, sí lo hace

\footnotetext{
${ }^{9}$ Deleuze, Diferencia y repetición, op. cit., p. 71.

${ }^{10}$ Vid. Duns Escoto, Ordinatio, I, d. e, 4.4 (ediciones, latina y española, mencionadas).

${ }^{11}$ Hardt, M., Deleuze: un aprendizaje filosófico, Buenos Aires, Paidós, 2004, p. 141; Heredia Rios, «Duns Escoto en Deleuze: Univocidad y distinción formal», op. cit., p. 9.

${ }^{12}$ Vid. Deleuze, Spinoza y el problema de la expresión, op. cit., p. 86, nota 24.
} 
al identificarlo con la Naturaleza, al simulacro de Dios, el rostro verdadero y auténtico de lo divino, Dios o Naturaleza. El mismo Baruj Spinoza indica: «Lo que ciertos hebreos parecen haber visto como a través de una nube, dado que admiten que Dios, el entendimiento de Dios y las cosas comprendidas por él son una y misma cosa» (Ética, II, 7, escolio) ${ }^{13}$.(¿Sería el latinizado Avicebrón, S. Ibn Gabirol, uno de ellos?) Gilles Deleuze comparte, una vez más, el punto de vista, para él materialista y panteísta, del filósofo de Amsterdam, y otros, y en esto basa además sus teorías del plano de consistencia y filosofía de la inmanencia, omnipresentes en su discurso filosófico.

Debemos recordar que, si bien el platonismo tuvo menos dificultades en penetrar en el orbe cristiano occidental, sobre todo tras San Agustín, siendo el legado aristotélico el que va a presentar mayores problemas; pero que el neoplatonismo, ya a partir de Plotino, en su última gran sistematización pagana, pese al proceso de bautismo y cristianización, nunca dejó de resultar conflictivo y merecer, cuando no la censura directa y aún la condena, al menos una extrema vigilancia, especialmente, claro, en la época medieval, pero también en la renacentista. Hablar de Juan Escoto Eriúgena, cuya obra Periphyseon o De divisione naturae fuera condenada al fuego por Inocencio III en 1225 (plagiada o casi, 'un cenón de extractos', en el Clavis Physicae de Honorio de Autun, ca. 1080$1153)^{14}$ y de la Escuela de Chartres, o de la teología negativa o de ciertas corrientes místicas, incluido el Maestro Eckhart, que en ocasiones alimentaron un panteísmo popular,

${ }^{13}$ Vid. Spinoza, B., Etica, Introducción, notas y trad. V. Peña, Madrid, Alianza, reed., 2011. Apunta Gilles Deleuze: «Y muchos comentadores pudieron reunir argumentos convincentes para mostrar que el Dios de Aristóteles, pensándose él mismo, piensa también todas las cosas que necesariamente derivan de ello: la tradición aristotélica tendía hacia el teísmo, a veces incluso hacia un panteísmo, identificando el cognoscente, el conocimiento y el conocido (los hebreos invocados por Spinoza son filósofos judíos aristotélicos)» (Deleuze, Spinoza y el problema de la expresión, op. cit., p. 95). Avicebrón es neoplatónico. Deleuze va algo más allá en su atrevido análisis, al considerar que, tal vez, en su Compendium grammatices linguae hebreae, encontraba ya y a la vez explicitaba una lógica de la exprexión según las estructuras gramaticales del hebreo, que funda una teoría de las proposiciones: 1) el carácter intemporal del infinitivo (caps. 5 y 13); 2) el carácter participal de los modos (caps. 5 y 33); 3) la concreción de determinadas especies de infinitivos, de los que uno al menos expresa la acción relacionada a una causa principal (cap. 12) (Deleuze, Spinoza y el problema de la expresión, op. cit., pp. 99-100, nota 12). (Algo similar-nos aventuramos a indicar nosotros, con más humildad que prudencia, pero en sentido contrario- le ocurre a Ramón Llull cuando intenta explicar la doctrina o dogma cristiano de la Santísima Trinidad a los musulmanes, tal vez fijándose en la estructura y raíz triádica de la lengua árabe, en la que se desenvolvía bien, según sus estudiosos.)

${ }^{14}$ Sobra recordar aquí que Domingo Gundisalvo (ca. 1115-1190), el traductor al latín del Fons vitae de Ibn Gabirol, dio un título similar a una obra en la que la presencia de las doctrinas de este autor judío es clara: De processione mundi (vid. D. Gundisalvo, De processione mundi, edición crítica y traducción española por $\mathrm{M}^{\mathrm{a}}$.J. Soto Bruna-C. Alonso del Real, Pamplona, EUNSA, 1999; A. Fidora, «Dominicus Gundissalinus and the Introduction of Metaphysics into the Latin West», The Review of Metaphysics, 66 (2013), pp. 691-712; Polloni, N., «Il De processione mundi di Gundissalinus: prospettive per un'analisi genetico-dottrinale», Annali della Facoltà di Lettere dell'Università di Siena, Siena, U. de Siena, 2014, pp. 73-86; Polloni, N., Domingo Gundisalvo, filósofo de frontera, Madrid, Sindéresis, 2013. Debemos recordar aquí, además, la relación de Amaurico de Bene con los chartreanos, y, tal vez, del propio David de Dinant, si éste nació y estudió en efecto en la escuela de Mantes, como se lee en 
y sembraron muchas dudas sobre ciertos dogmas de fe, es tan sólo hablar de una tradición u ola recurrente, y que corre en paralelo, aunque sin confluir o fusionarse, con otra tradición más peligrosa, la tradición de un materialismo y panteísmo real. Se mencionaron antes algunos nombres, y no volveremos sobre ello.

La sombra de la sospecha, como es sabido, cayó incluso, a caballo entre Medievo y Renacimiento, sobre un hombre de la misma institución eclesiástica tan altamente considerado como el cardenal Nicolás de Cusa (Cusa, Tréveris, 1401-Todi, Umbría, 1464), por cierto, una de las fuentes tardías para el conocimietno de las doctrinas de David de Dinant (especialmente en su Tetralogus de non aliud, compuesto en Roma en enero de 1462). Merece la pena, con el historiador dominico G. Théry, por ejemplo, recordar el contexto de esta acusación (y, tal vez, revancha). En 1449, Juan Wenck de Herrenberg (1400-1460), representante de la escuela teológica de Heidelberg, escribe un duro texto, De Ignota Litteratura, en el que refuta el De Docta Ignorantia del Cusano, acabado en Cusa en 12 de febrero de 1440. Wenck, que en el Concilio de Basilea se había mostrado partidario del bando conciliarista frente a quienes apoyaron a Nicolás V, entre ellos el $\mathrm{Cu}$ sano, moderado conciliarista hasta 1438, dejaba caer allí una velada acusación de panteísmo contra el cardenal, y amigo de Papas, al ver en su texto doctrinas «disonantes con la fe, ofensivas a los espíritus piadosos y de naturaleza dirigida a perturbar vanamente el servicio de Dios», próximas a los begardos de Estrasburgo: «Ymmo plus desipit olim Beghardis Argentinensibus per eorum episcupum dampnatis, qui dicebant se ese Deum per natura, sine distintione». Pero el Cusano no se calla, y menos ante una acusación de tal gravedad. Escribe de inmediato una réplica, su famosa Apologia doctae ignorantiae (1449) (entre otras ediciones, anotemos además las de Basilea, 1565, para las páginas que siguen, 72-73; cita en él, entre otros muchos autores, entre los árabes, a Avicena y Algazel, ni rastro del Fons vitae del judío Ibn Gabirol; tampoco evita citar a otros autores cristianos siempre envueltos en polémicas y críticas, como Thierry de Chartres o al mismísimo Meister Eckhart). Allí nos da un dato de interés. Dice que es muy peligroso poner en manos de personas de pocas luces ciertos libros, y alude a cuatro autores que nos son bien conocidos entre los eternos sospechosos, Dionisio el Areopagita, Mario Victorino, Escoto Erigena y David de Dinant. Parece apuntar, en general, por lo tanto, a una tradición neoplatónica.

algunas fuentes (dados lo vínculos entre ambas escuelas: Chartres y Mantes, vid. M. l'abbé A. Clerval, Les Ecoles de Chartres au Moyen Âge (du Ve au XVIe siècle), Paris, Picard, 1895, pp. 62, 80 y 360, en Théry, O., Autour du décret de 1210. I David de Dinant. Étude sur son pantéisme matérialiste, Kain (Bélgica), La Sulchoir, 1925, p. 12, nota 5). Pensemos, además, que Guillermo de Conches fue acusado de panteísmo siendo cuestionado además su atomismo (se movía a la sombra de un cierto materialismo, pero la duda tal vez ofendía al autor y a la escuela, muy vigilados siempre), las autoridades cerraron los ojos ante las doctrinas de la relación entre el mundo y Dios de Bernardo de Chartres, dándolas por buenas, otra cosa son las querellas de escuela. Y Gilberto de la Porrée, pese a Guillermo de de SaintThierry y Bernardo de Claraval, logró evitar condenas explícitas en el concilio de Reims de 1148. Este grupo de neoplatónicos medievales siempre estuvo bajo sospecha de la Iglesia. Si vamos cara atrás nos encontraremos la figura de Juan Escoto Eriúgena, autor tan incómodo siempre. 
[28] ... Posteriormente leí la tercera conclusión que afirma que se obtiene de la docta ignorancia: que la quididad es intangible. / El maestro dijo: «Aunque también es inteligible, según él propone, sin embargo nunca es entendida en acto, así como Dios es sumamente inteligible y el sol sumamente visible. De la coincidencia de los opuestos en el máximo no se sigue este 'veneno del error y de la falsedad', a saber, la destrucción del fundamento del primer principio de todo conocimiento, como deduce el adversario. Pues aquel principio es primero en cuanto a la razón discursiva, pero de ninguna manera en cuanto al intelecto que ve, según se ha tratado de esto más arriba. / Ni es cierto, si Dios es todo lo que es, que por ello no haya creado todas las cosas de la nada. Pues, como sólo Dios es la complicación de todo el ser de cualquier cosa que existe, al crear, ha explicado el cielo y la tierra; o mejor, puesto que Dios es todas las cosas por el modo divino de complicación intelectual, es también Explicador, Creador, Autor de todas las cosas y de todo lo que pueda decirse sobre esto; así arguye el gran Dionisio / Y si fueron los begardos los que, según escribe, decían que eran [29] Dios por naturaleza, con razón fueron condenados, como también Almerico fue condenado por Inocencio III en concilio ecuménico, sobre lo cual puedes leer en el capítulo Damnamus De Summa Trinitate; Almerico no comprendió bien cómo es que Dios es todas las cosas por modo de complicación; algunos de sus errores son citados por Juan de Andrés en Novella. Sucede que los hombres de poca inteligencia caen en el error cuando buscan las cosas altas sin la docta ignorancia; no sólo se quedan ciegos en los ojos de la mente por la infinidad de la luz del sumo inteligible, sino que también, sin tener conocimiento de su ceguera, creen que ven; $y$, como si vieran, se endurecen en las afirmaciones; como los judíos que, careciendo de espíritu, son conducidos por la letra a la muerte [vid. II Cor 3, 6]. Como también aquellos que, viendo a los sabios, piensan que son ignorantes y que están equivocados cuando leen en ellos estas cosas insólitas y también cuando descubren que ellos entonces se creen sabios al conocer que son ignorantes. Por eso, todos los santos advierten correctamente que la luz intelectual será quitada a aquellos que tienen una débil visión mental. De ningún modo se debe mostrar a éstos los libros de San Dionisio, el Ad Candidum Arrianum de Mario Victorino, la Clavis Physicae de Teodoro, el Peri Physeos de Juan Escotorígena, De Tomis de David de Dinant, los Commentaria in Propositiones Proculi del hermano Juan de Mosburgo y otros libros parecidos ${ }^{15}$.

\footnotetext{
${ }^{15}$ Nicolás de Cusa, Cardenal / Wenck, Johannes; Apología de la docta ignorancia / Nicolás de Cusa; La ignorada sabiduría / Juan Wenck; introducción, traducción y notas de S. Sanz, Pamplona, Servicio de Publicaciones de la Universidad de Navarra (col. Cuadernos de Anuario Filosófico. Serie universitaria, núm. 24), 1995, pp. 107-110. Notas aclaratorias sobre el contenido por sus editores: Juan de Andrés, Novella super primo libro decretalium, título De Summa Trinitate et Fide Catholica, cap. Damnamus, vol. 1, p. 5 verso, col. 2, Venecia, 1489; De generatione divini Verbi ad Candidum Arrianum, Cayo Mario Victorino, el Africano, ca. Cartago, 285-m., tal vez, Roma, 1363, ed. Migne, PL. VIII, co. 109191040; muy belicoso con el cristianismo, desde las posiciones de Plotino y Porfirio de Tiro, antes de su muy tardía conversión, que sorprendió a todos, Agustín, Confesiones, VIII, 2, 3; el Clavis Physicae de Honorio de Autun, ca. 1090-1115, errata debida, piensan algunos intérpretes, a que perdido el nombre de Honorio en el codex cusanus, pasó a ocuparlo el interlocutor principal del diálogo de la primera parte, 'Teodosio', pero tal vez pueda deberse a una mala transcripción de 'H(The)on(d)or(s)io', no
} 
No nos da otros títulos de libros peligrosos, y menos habríamos de esperar de los condenados por los concilios, que él, debido a su infinita curiosidad o voracidad intelectual, a sus medios y privilegios, a sus desplazamientos, seguro que poseyó, pero que, por prudencia, no legó, como los demás, al Hospital de Cusa, y que tal vez se había llevado a Roma (esto opina, por ejemplo, el ya mencionado el P. O. Théry) ${ }^{16}$.

\section{Haecceitas}

Vistos estos tres puntos, tres anillos encadenados y encantados como en el cuento de Boccaccio, «univocidad del ser», «diferencial formal» y «potencia» (con la distinción entre potentia absoluta y potentia ordinata), permítasenos ahora introducir un término muy conocido para ambas familias filosóficas, la de los escotistas y la de los deleuzianos, nos referimos -en referencia al proceso de individuación-al término haecceitas (noción de individuo), término que los segundos toman prestado de los primeros. Es noción cuya génesis se puede remontar y rastrear hasta la escuela helenística de los estoicos ${ }^{17}$.

deja de ser especulativo; por lo demás, en la biblioteca del Cusano existía un ejemplar de esta obra

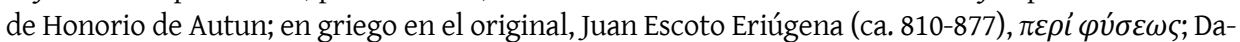
vid de Dinant, De Tomis, id est de divisionibus (en realidad, tomi, pegado en el texto al nombre anterior, coma, y el nombre del autor, recibió otros títulos, De atomorum, por ejemplo); Bertolo de Mosburgo, Commentaria in Propositiones (in Elementationem Theologicam) Procli, escolástico dominico del siglo XIV, m. después de 1350, intenta fundamentar filosofías varias en el marco neoplatónico de la filosofía de la unidad.

${ }^{16}$ Théry, O., Autour du décret de 1210. I David de Dinant. Étude sur son pantéisme matérialiste, op. cit., p. 27. Como balance general, vid. Jundt. Auguste, Histoire du pantheisme populaire au Moyen Âge et au Seizième siècle, Frankfurt am Main, Minerva GMBH, Unveänderter Nachdruck, 1964; en donde vuelven a aparecer muchos de los nombres ya mencionados, tanto por J. Weck, como por el cardenal de Cusa, o nosotros mismos (además del Pseudo-Dionisio, Escoto Eriúgena o Joaquin de Fiori, para el siglo XIII, estudia los casos de Dinant y Amaury, de los los panteístas valdenses, del panteísmo de las escuelas [pp- 34-35], y de Ortlieb de Estrasburgo y los ortlibianos, pp. 1-42).

${ }^{17}$ Vid. González Fernández, M., «Diferencia y repetición: estoicismo \& escotismo», en Coloquio Internacional «Filosofía Medieval: em curso e em toda a extensâo». Gabinete de Filosofía Medieval, dir. J. Meirinhos. Porto (Portugal). Facultade de Letras da Universidade do Porto (FLUP) / Instituto de Filosofía. 12-14 de janeiro de 2017. (No se han publicado Actas, y tampoco había compromiso de hacerlo). Giordano Bruno de Nola, este sí que panteísta y filósofo de la inmanencia, carga contra este concepto en el Diálogo III del De la causa, principio, et Uno (Londres, 1584) (vid. González Fernández, M., «Alcuni cocullati suttili metafisici: Juan Duns Escoto \& Giordano Bruno de Nola», Cap. 11, en M. Lázaro Pulido; F. León Florido; E. Montoro Montero (eds.), Pensar la Edad Media Cristiana: la presencia de la teología medieval en el pensamiento moderno. Madrid, Porto, Editorial Sindéresis, 2017, pp. 243294). Por supuesto, toda esta crítica hay que entenderla desde aquella óptica, panteísta y materialista, que no difiere mucho a la luego formulada por Baruj Spinoza, donde se identifica a Dios con la Naturaleza, y se habla de la perpetua vicisitud de las cosas, de lo finito, de los individuos, sean estos humanos o instituciones, religiones, imperios o cualquier tipo de leges. (Paradójicamente, en muchos de estos puntos, esta suerte de 'neoplatonismo materialista' - Deleuze quiere, en la línea del filósofo de Sils-María, «invertir el platonismo», en abstracto, y como estereotipo o canon del pensamiento representativo- coincide con el aristotelismo radical, con la tradición del averroísmo latino o paduano.) Comulga así, filosóficamente, con Maquiavelo, Montaigne o Pomponazzi. 
La haecceitas es para el Doctor Sutil la diferencia formal ultimísima del individuo concreto. Podríamos afinar más el significado con estudiosos del autor (E. Gilson, J. A. Merino, R. Ramón Guerrero o León Florido, etc. ${ }^{18}$, pero bástenos con la voz muy autorizada de J. Pérez de Tudela Velasco, para quien sería:

[La] diferencia última, con un puro quale cuyo ser propio es exclusivamente virtual y que actualiza en su intensidad gradativamente determinada la actualidad de la naturaleza desde el interior mismo de la razón formal. En el lenguaje técnico de Escoto, es entidad, sí, pero entidad no-quiditativa que es la haeccitas, se designa bajo la forma precisa de "última actualidad de la forma"19.

Vayamos ahora a nuestros post-estructuralistas y post-modrernos. En uno de los textos incluidos en Mille plateaux (capitalisme et schizophrénie) $(1980)^{20}$, obra conjunta de G. Deleuze y F. Guattari, Cap. 10, «1730: Devenir-intenso, devenir-animal, devenir-imperceptible», establece una división en dos partes: en la primera, fija toda una serie de estampas o «Recuerdos» - de un espectador, de un naturalista, de un bergsoniano, de un brujo (I, II y III), de un teólogo, de un espinozista (I y II), de un planificador, de una molécula, del secreto)-; en la segunda parte, hablará de «Recuerdos y devenires, puntos y bloques» y, finalmente, de un «Devenir música». En el primer panel, entre el 'espinozista II' y el 'planificador', hay una extensa reflexión sobre el principio de individuación (que dirían los clásicos) y que rotula, «Recuerdos de una haecceidad». Al principio nos sorprende, por inesperado. En la nota 24 nos da la clave de este pequeño enigma. Hay, por supuesto, un recordatorio o evocación de la fórmula o noción de Juan Duns Scoto, pero revocando su etimología. Así nos dice a propósito de la haecceidad:

A veces se escribe ecceité, derivado de la palabra ecce, 'he aquí. Es un error, puesto que Duns Scoto ha creado la palabra y el concepto a partir de haec, 'esta cosa'. Pero es un error fecundo, puesto que sugiere un modo de individuación que no se confunde precisamente con el de una cosa o un objecto ${ }^{21}$.

El reajuste, con todo, finalmente, se queda en eso, en mera adaptación a la cartografía deleuziana (grados de intensidad, dimensiones internas, desencadenamiento de fuerzas), que, por cierto, tiene mucho de nietzscheana y aún de espinozista ('nadie supo

${ }^{18}$ Vid. González Fernández, M., «Alcuni cocullati suttili metafisici: Juan Duns Escoto \& Giordano Bruno de Nola», op. cit., pp. 274-275.

${ }^{19}$ Pérez de Tudela y Velasco, J., Identidad, forma y diferencia en la obra de Juan Duns Scoto: una aproximación matemática al problema de su interpretación, Madrid, Universidad Complutense de Madrid, 1981, p. 263. Alude al pasaje del autor, Opus Oxoniense II, d 3, pars 1 qq. 5-6 nn. 179-180.

${ }^{20}$ Deleuze, G., Guattari, F., Mil plateaux (capitalisme et schizophrénie), Paris, Les Editions de Minuit, 1980; en español, Mil mesetas (capitalismo y esquizofrenia), traducción de J. Vázquez Pérez, Valencia, Pre-Textos, 1988.

${ }^{21}$ Deleuze, Guattari, Mil mesetas (capitalismo y esquizofrenia), op. cit., p. 310, nota 24. Nosotros dudamos que ambas dimensiones no estén ya en la categoría, de examinarla desde el estoicismo. 
nunca todavía qué puede dar de sí un cuerpo') 22 . Nace una nueva «subjetividad», que puede estar eventualmente encarcelada, pero que, contra toda negación e inercia, afirma su diferencia. Apunta abiertamente a un individuo «no cosificado» ${ }^{23}$.

Para ellos:

Un cuerpo no se define por la forma que lo determina, ni como una sustancia o un sujeto determinados, ni por los órganos que posee o las funciones que ejerce. En el plano de consistencia, un cuerpo sólo se define por una longitud y una latitud: es decir, el conjunto de los elementos materiales que le pertenecen bajo tales relaciones de movimiento y de reposo, de velocidad y de lentitud (longitud); el conjunto de los afectos intensivos de lo que es capaz, bajo tal poder o grado de potencia (latitud). Tan sólo afectos y movimientos locales, velocidades diferenciales. Corresponde a Spinoza haber puesto de manifiesto estas dos dimensiones del Cuerpo, y haber definido el plano de la Naturaleza como longitud y latitud puras. Latitud y longitud son los dos elementos de una cartografía. / Existe un modo de individuación muy diferente del [al] de una persona, un sujeto, una cosa o una sustancia. Nosostros reservamos para él el nombre de haecceitas ${ }^{24}$.

Claro está, es una visión materialista, una filosofía de la inmanencia, que para nada compartiría nuestro beato (que, en todo caso, y a saber por qué razones, no llegó a santo). Una concepción orgánica y dinámica del individuo, casi 'energética', en esto se

22 «Lo que puede un cuerpo es la naturaleza y los límites de su poder de ser afectado [E, III, 2, esc.: 'Nadie en efecto ha determinado hasta el presente lo que puede el cuerpo [...] Pues nadie, hasta el presente, ha conocido la estructura del cuerpo']» (Deleuze, Spinoza y el problema de la expresión, op. cit., pp. 208-209). En otro lugar: «Así los modos en su esencia son expresivos: expresan la esencia de Dios, cada uno según el grado de potencia que constituye su esencia. La individuación del finito en Spinoza no va del género o de la especie al individuo, de lo general a lo particular; va de la cualidad infinita a la cantidad correspondiente, que se divide en partes irreductibles, intrínsecas o intensivas» (Deleuze, Spinoza y el problema de la expresión, op. cit., p. 192).

${ }^{23}$ Cosificación, pero no en el sentido marxista, por ejemplo, y menos en el existencialista (con su propia teoría o filosofía del sujeto, el demonio del estructuralismo), aunque con cierta relación remota (muy remota, y aún en Foucault más que en Deleuze) con la Escuela de Frankfurt o A. Gramci, sino tan sólo en el marco o universo teórico de un lacanismo castrante ('Y este ha sido uno de los mejores logros del psicoanálisis: desarrollar en todos los sentidos la extraordinaria equivocidad de lo sexual', Deleuze, Guattari, Mil mesetas (capitalismo y esquizofrenia), op. cit., p. 448; es sabido que este autor consideraba que el lacanismo, junto al marxismo, eran las dos últimas grandes burocracias de Occidente) o en el de una microfísica del poder lesiva, coercitiva, paralizante, entorpecedora, 'terreno estriado', aquella de que habla y denuncia Michel Foucault. Ahora bien, la 'diferencia-en-sentido-positivo' puede llevar a cualquier escenario, pues es también, por ejemplo, el de la nueva y preocupante tecno-genética, del nacionalismo supremacista o del individualismo o atomismo extremo solipsista y nihilista. Entre los seguidores de Gilles Deleuze, por supuesto, hay de todo un poco, y ya el mismo alertó sobre el peligro que podían suponer algunas derivas o líneas de fuga cara al micro-fascismo, o directamente al fascismo, o a falonarcismos sin cuento. No se trata aquí de enmendarle la plana al maestro.

${ }^{24}$ Deleuze, Guattari, Mil mesetas (capitalismo y esquizofrenia), op. cit., p. 264 (enlaza con esto la nota 24 de la p. 310 ya mencionada). 
queda la haecceitas en Deleuze-Guattari. Cómo el lector medievalista quedará extrañado por tan curiosa novedad, y exigirá mayor precisión, se la daremos:

Son haecceidades, en el sentido de que en ellas todo es relación de movimiento y de reposo entre moléculas o partículas, poder de afectar y ser afectado... haecceidades que no son simplemente ordenamientos, sino individuaciones concretas válidas por sí mismas y que dirigen la metamorfosis de las cosas y de los sujetos. Entre todos los tipos de civilización, Oriente tiene muchas más individuaciones por haecceidad que por subjetividad y sustancialidad: así, el haï-ku debe implicar indicadores como otras tantas líneas flotantes que constituyen un individuo complejo....plano de la haecceidades en un caso, que sólo conoce velocidades y afectos...Aiôn, que es el tiempo indefinido del acontecimiento, la línea flotante que sólo conoce las velocidades, y que no cesa a la vez de dividir lo que ocurre en un déjà-là y un pas-encore-là, un demasiado tarde y un demasiado pronto simultáneos, un algo que sucederá y que a la vez que acaba de suceder. Y Cronos, que, por el contrario, es el tiempo de la medida, que fija las cosas y las personas, desarrolla una forma y determina un sujeto...Boulez...dos modos de individuación, dos modos de temporalidad ${ }^{25}$.

En alguna entrevista habla de una (nueva) «individualidad de acontecimientos»: o sea, al margen del régimen de la sustancia, libre, en su infinita potencia material de relaciones y flujos, subjetividades pre-individuales (también las define así) ${ }^{26}$.

${ }^{25}$ Deleuze, Guattari, Mil mesetas (capitalismo y esquizofrenia), op. cit., pp. 264-265. «Pero no hay que pensar que la haeccedidad consiste simplemente en un decorado o en un fondo que situaría a los sujetos, ni en apéndices que fijarían al suelo las cosas y las personas. Todo el agenciamiento en un conjunto individuado resulta ser una haecceidad: se define por una longitud y una latitud, por velocidades y afectos, independientemente de las formas y de los sujetos que sólo pertenecen a otro plano...A lo sumo. Se destinguirá las haecceidades de agenciamientos (un cuerpo que sólo es considerado como longitud y latitud), y las haecceidades de inter-agenciamientos, que señalan también las potencialidades del devenir en el seno de cada agenciamiento (el medio de cruzamiento de las longitudes y latitudes). Pero las dos son estrictamente inseparables...Así hay que percibir. Las relaciones, las determinaciones espacio-temporales no son predicados de la cosa, sino dimensiones de las multiplicidades...El plano de consistencia sólo contiene haecceidades según líneas que se entrecruzan: las formas y los sujetos no pertenecen a ese mundo. ..Una heicceidad no tiene ni principio ni fin, ni origen ni destino; siempre está en medio. No está hecha de puntos, sólo está hecha de líneas. Es rizoma» (Deleuze, Guattari, Mil mesetas (capitalismo y esquizofrenia), op. cit., p. 266). El lector deberá ir al acontecimiento mismo del texto, donde encontrará, como ejemplos o elementos esclarecedores que se cruzan, referencias a Maurice Blanchot y el «indifinido de la terceras persona» (vid. Blanchot, M., L'entretien infini, París, Gallimard, 1969; L'espace littéraire, Paris, Gallimard, 1955, etc), los «métodos pasivos» de la escritura poética china, la «música repetitiva» a lo Steve Reich o Phil Glass, ya se habló arriba de P. Boulez (vid. Boulez, P., Par volunté e par hasard: entretiens avec Célestin Deliège Broche, Paris, Eds. du Seuil, 1975). Tiene que ver con la figura del rhizome (así titulan ambos la introducción del libro conjunto, que fue primero artículo independiente), que atenta directa y virulentamente, si se quiere, contra la figura totémica del árbol ontológico porfidiano, su fijación taxonómica de especies y géneros (para ellos, metáfora viva en cierto sentido del Decálogo bíblico o del sistema de categorías aristotélico). (Vemos de nuevo una encubierta evocación del legado estoico.)

${ }^{26}$ En efecto, el individuo de Gilles Deleuze (Benedictus Spinoza), despojado del régimen de la sustancia (al tiempo que excarcelado del régimen poder, si se quiere, que fabrica sujetos sujetados, 


\section{Materia prima}

Pensar la materia primera sin forma alguna. Recordemos el esquema de una única Sustancia (Materia, Dios, natura est deus in rebus, Bruno, Spinoza), infinitos atributos, modos infinitos. Esta es una paradoja del pensamiento escotista, un accidente coherente añadido a éste, por la que se aleja del aristotelismo y de la filosofía escolástica cristiana derivada de él (caso curioso es el de Tomás de Aquino). Sin llegar a romper del todo, nunca, con éste. Se trata, en efecto, de una cuestión tan sólo formal y muy puntual. Al punto de no generar alarma en la ortodoxia. Líbrenos Dios, sive Natura, por lo demás, de atribuirle al Doctor Sútil cualquier atisbo de materialismo, claro está. Pero es un hecho que choca, en principio, en quién afila tanto el puntero y lleva tan lejos la noción de formalitas («especie especialísma», P. M. Oromí) ${ }^{27}$.

Exponía así el problema el siempre recordado A. Pérez-Estévez (q.p.d.):

La materia prima escotista, por su consistencia substancial, aunque mínima, si la potencia de Dios así lo decide, existe sola sin la forma, debido a que el ser en acto de la materia prima por el que simplemente es, le pertenece esencialmente y no proviene de la forma. Sin embargo, en el orden actual establecido por Dios, la materia prima, por su ser en acto mínimo, es esencialmente dependiente del acto formal para poder existir como parte de una sustancia natural compuesta [Sabemos que, para Tomás de Aquino, es imposible por contradictorio que la materia prima, que es pura potencia, exista o sea en acto, Quodlibetum III, q. 1, a. 1]: «Menos parece que pueda existir el accidente sin sujeto que la materia sin forma debido a que el sujeto tiene alguna causalidad con respecto al accidente, mientras que la materia no depende de la forma bajo ningún tipo de causalidad; ahora bien, el accidente puede, por alguna potencia, existir sin sujeto [como sucede milagrosamente en la eucaristía, según el cristianismo]; por tanto, la materia [puede existir] sin la forma' [Reportata pa-

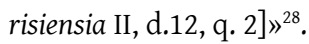

organiza la vida, ordena y manda), como flujo de relaciones, actualizador infinito de infinitas potencias, rizomático, desterritorializado, nómada, mutante, haecceidades sin formas especialísimas (en tanto que abierto simpre a nuevas formas), es una sujeto arborescente (en el que conviven o coexisten figuras, tendencias, ritmos, siempre plurales, siempre activos), poblado de grados de potencia, cargado de simulacros. (Empleamos el término «arborescente» de modo consciente en un sentido no-deleuziano: más en clave del mundo digital o computacional, por ejemplo, en la figura de los entramados de los conceptual maps o big data, como universos abiertos y en expansión, en construcción, sensibles al deseo y voraces de acontecimiento.)

${ }^{27}$ P. Miguel Oromí, «Introducción», en Duns Escoto, Obras del Doctor sutil Juan Duns Escoto, op. cit., t. I, p. 47.

${ }^{28}$ Pérez-Estévez, A., «Juan Duns Escoto: conceptos y doctrinas fundamentales de su filosofía», Agora. Papeles de Filosofía, 23 (2004), n. 2, p. 127. «Materia y forma constituyen los elementos de toda quididad o naturaleza común, a los que hay que añadirle la hecceidad o formalidad individualizante, para constituir el individuo existente. Materia, forma, naturaleza común u hecceidad son entidades metafísicas y realidades del individuo. La forma es acto y produce el acto por el que la materia se perfecciona para constituirse en parte de la sustancia individual. La materia, por el contrario, se encuentra en potencia para recibir de la forma el acto por el que se perfecciona y se constituye como 
La materia es, en acto, potencia (Comentario a las Sentencias [Ordinatio], Libro II, distinción 12, cuestiones 1 y 2) (como indica, al comentar este pasaje, León Florido; no lo ve tan claro o matiza con reservas, el P. M. Oromí) ${ }^{29}$ Una rareza, casi anomalía. Pero el mundo del Doctor Mariano está lleno de ellas, piénsese sino en su cosmología, que podía devenir en lo diferente y vuelve a lo mismo, o en su doctrina de la inmaculada concepción de la Virgen María. (Ya se ha mencionado, de pasada, arriba, el tema doctrinal capital de la eucaristía.) Se le llamó por ello también, doctor sutil.

Pensar la materia sin forma: por supuesto, que unos y otros, escotistas y deleuzianos (o espinozistas, o brunianos) puedan llegar a este punto, no significa que converjan para nada en su pensamiento, como era de esperar, pues unos defienden un monoteísmo de la trascendencia (y del libro) y otros, los últimos, un monoteísmo de la inmanencia (tomamos el término de Miguel A. Granada Martínez, el maestro). Es la diferencia, pero radical, unos son cristianos y otros materialistas, no es poco. Para el Doctor Sutil todo se reacomoda ante la condición omnipotente de la Voluntad divina.

\section{Coexistencia de formas}

Gran parte de la tradición agustiniana, hasta las condenaciones de 1277 del obispo Étienne Tempier, admitía la posibilidad de coexistencia de varias formas configuradoras en el mismo sujeto: y este franciscano, J. Duns Escoto, también, antes de exigírsele rectificación; como en el caso del jesuita Francisco Suárez, por cierto. Tomás de Aquino, que va a ser también reprobado en las mismas condenas parisinas (en este caso, no por caos, concentración, acumulación o condensación de formas, sino, por algo más grave, por hacer de la materia el principio de individuación), precisamente, la va a reprochar a Selomón Ibn Gabirol, el latinizado Avicebrón, el famoso autor de la Fuente de la vida, entre otras doctrinas, el haber caído precisamente en este error:

Avicebrón y ciertos de sus seguidores dicen que según el orden de los géneros y de las especies hay diferentes formas sustanciales que sobrevienen una tras otra, así como existe la sustancia, el cuerpo, el viviente y el animal. Dicen, por tanto, que hay una forma sustancial para la que existe la sola sustancia, después otra que da cuenta [se corresponde con] del cuerpo, luego otra que hace al vivente, luego otra que hace al animal, después otra por la cual el hombre es hombre ${ }^{30}$.

parte de la sustancia individual» (Pérez-Estévez, «Juan Duns Escoto», op. cit., p. 125). De interés y del mismo autor: Pérez-Estévez, A., El concepto de materia al comienzo de la escuela franciscana de Paris. Zulia (Venezuela), Universidad de Zulia, 1976; Pérez-Estévez, A., La Materia, de Avicena a la escuela franciscana: (Avicena, Averroes, Tomás de Aquino, Buenaventura), Maracaibo (Venezuela), Ediluz, 1998.

${ }^{29}$ Vid. León Florido, F., La filosofía del siglo XIV, Madrid, Escolar y Mayo, 2013; M. Oromí, «Introducción», en Obras del Doctor sutil Juan Duns Escoto, op. cit., t. I, pp. 46-47.

${ }^{30}$ Tomás de Aquino, Quodlibeta, XI, a. 5, corp. Veamos todavía otro pasaje: «Avicebrón admite que, según el orden de los géneros y de las especies, hay una serie de muchas formas sustanciales en una sóla y la misma cosa; así, por ejemplo, en tal hombre individual hay una forma por la que es 
Las capas de formas todavía se podrían multiplicar, y además, en el caso del escotismo y con importancia, habría que añadir o agregar a esta floresta barroquizante una última: la forma especialísima de cada individuo concreto, o talidade. El argumento de la ortodoxía, contra esta doctrina, será básicamente que no se puede confundir lógica con física u ontología ${ }^{31}$. Hay, pues, según este primerizo Doctor Sutil, estratos y capas de formas, terrazo sobre terrazo, sedimento sobre sedimento, registros formales sobre registros formales, siempre coexistindo. Lo que nos dicen y añaden los deleuzianos, que (nos) abren este individuo a todo campo de devenires, es que estas formas, mateniendo la autonomía, se pueden activar independientemente, y que hay otras modalidades o grados positivos de diferencia, intensidades posibles, en cada cuerpo. En la cartografía rizomática del individuo concreto en la ontología deleuziana o en la nomadología derivada de ella, de la suya y de sus discípulos, se podrían añadir otras: por ejemplo, relativas al género. Le viene de perlas, por ejemplo, al feminismo de la diferencia sexual frente al feminismo del género. (Casi volvemos a Sigmund Freud, pero sin perversiones o el maditismo de lo patológico.) Con ello, se puede entender algo de aquel deveniranimal, devenir-mujer, devenires varios, a desplegar, en condiciones propicias de acontecimiento, en un terreno liso y no estriado, por un sujeto concretísimo nómade, variante, el mentado en Mil mesetas, y otros lugares: se abre por lo tanto el campo u horizonte a toda metamorfosis ontológica. Así lo vió un viejo deleuziano español ${ }^{32}$.

\section{Modos intrínsecos}

Gilles Deleuze nos ha regalado con unas famosas lecciones tituladas En medio de Spinoza, dictadas en la Universidad de Vincennes entre el 25 de noviembre de 1980 y el 31 de marzo de 1981, una auténtica bendición, con 15 vibrantes conferencias e intervenciones sobre el cuerpo

sustancia, otra por la que es cuerpo, otra por la que es cuerpo animado, etc.» (Tomás de Aquino, In II De anima, lect. 1). (Las obras completas en español, ya se adelantó, están editadas en la Biblioteca de Autores Católicos, Madrid.)

${ }^{31}$ Vid. Brunner, F., Platonisme et aristotélisme: la critique d'Ibn Gabirol par saint Thomas d'Aquin, Louvain/Paris, Publications universitaires de Louvain/B. Nauwelaerts, 1965; que recoge todas y cada una de las referencias críticas a esta problemática, contra Avicebrón, en el Aquinate.

${ }^{32}$ No es idea nuestra. Tiene padre. Lo ha visto certeramente el introductor del pensamiento deleuziano en el Estado español, Pancho Martínez: «Este devenir no es una imitación, no consiste en 'hacer cómo'; no es nada imaginario, sino algo real, completamente real. Este devenir real, sin embargo, no produce otra cosa que él mismo, es un movimento puramente inmanente, no tiene un objetivo fuera de él. Mediante los diferentes devenires se establecen relaciones con otro, pero sin dejar de ser uno mismo. Así, devenir animal, o devenir mujer, o devenir niño, no consiste en imitar a los animales, a las mujeres o a los niños o en convertirse en animal, mujer o niño, sino en recuperar aspectos que de animal, mujer o niño hay en todos o establecer con estos aspectos una relación sincrónica. Aquí Deleuze retoma la tradición agustiniana medieval que defendía la pluralidade de formas coexistiendo en un mismo individuo, lo cual introducía una radical pluralidad en el seno del mismo y de su individualidad. Esta pluralidad permanecía virtual, pero podía actualizarse en determinadas circunstancias» (Martínez Martínez, F.J., Ontologia y diferencia; la filosofía de Gilles Deleuze, Madrid, Orígenes, 1987, p. 49). Hay aquí, opinamos con él, algo más que un cierto y vago aire de familia. 
de Spinoza. Es un Deleuze en estado puro, y aun podríamos añadir que en estado de gracia. Todas tienen interés, claro, pero será en la lección 12ª titulada «Teoría de la individuación. Infinitamente pequeños, relaciones diferenciales y grados de potencia» (10 de marzo de $1981)^{33}$ en la que nos fijaremos aquí, ya que en ella encontramos la perla vermeeriana que andamos buscando en este apartado, la metáfora de la «blancura» a propósito de la noción de la «intensidad», que pone de nuevo en conexión (enganches múltiples) al Spinoza de Deleuze con el filósofo medieval tardío o gótico Juan Duns Escoto. Aparece, blanco sobre negro, cuando el conferenciante está hablando y comentando la tercera capa de individuación, o sea la que corresponde a la naturaleza del individuo concreto, grado de potencia diferencial, con su correspondiente tercer grado de conocimiento, o sea la intuición. Es entonces cuando, espontáneamente (o necesariamente), irrumpe, aparece (se expresa), la noción misma de «intensidad» -que remite a la del conatus; nos recuerda Deleuze que ya Martial Geroult había hablado a este propósito de «vibración» (se puede vincular, ya se dijo, a la noción estoica de tonos) -, y, en este sentido, para hacer pedagogía, objetivo capital común al filósofo de Amsterdam, alude a esta metáfora: la de la «blancura» (del muro, de la pared o de lo que sea.) La metáfora en sí, por lo demás, le cuadra bien al Doctor Mariano. Más que ampliar, profundiza aquí viejos conceptos, los redimensiona. Leyendo a Spinoza, Gilles Deleuze la usa para hablar de los individuos concretos como seres modales, compuestos de infinitos flujos de partes infinitamente pequeñas, que se relacionan con otros flujos, configurando, finalmente, el grado de la potencia diferencial de la entidad o realidad de la haecceidad. Aplicada a los modos, se encuentra en el Tratado breve de aquél: «Por ejemplo, si todo el muro es blanco no existe en él un esto o un aquello» (Tratado breve, II, 20,3) ${ }^{34}$. (Como quiere Spinoza y retoma Deleuze, metáfora sobre metáfora: 'el mundo mental de la luz es el lenguaje de la univocidad pura'; añadimos nosotros; y pensando en la arquitectura gótica, la luz es la clave de este movimiento artístico, apunta a la desmaterialización activa.) Deleuze parte de aquí, y de la noción aviceniana de la «indiferencia», que él matiza (de nuevo, con alusión puntual al mismísimo Avicena y a Escoto) ${ }^{35}$. De lo neutro se pasa, o salta,

${ }^{33}$ Deleuze, En medio de Spinoza, op. cit., 384-420.

${ }^{34}$ Spinoza, B., Tratado breve, Introducción, notas y traducción de A. Domínguez Basalo, Madrid, Alianza, 1990, p. 149, nota 8.

${ }^{35}$ Deleuze, Spinoza y el problema de la expresión, op. cit., p. 186. En otros lugares, para explicar a Spinoza, vincula precisamente a Juan Duns Escoto con Avicena, a propósito de la noción de «lo indiferente»: el ser es indiferente (tercer estado de la esencia) (Dios o criaturas, finito o infinito, abstracto o concreto, universal o singular, lógico o físico, la fórmula del animal tantum) (vid. Deleuze, En medio de Spinoza, op. cit., pp. 489-490), mientras no pase al plano de la existencia. Así: «Duns Scoto da contra Santo Tomás el mismo golpe al nivel del ser que el que da Avicena al nivel de la esencia», el «ser en tanto que ser» no es ni finito ni infinito, etc., es neuter, neutro: «Él [Duns Escoto] descubre una nueva esfera, la del ser en tanto que ser, y luego la neutraliza. Se trata de un concepto [finalmente] puramente lógico» (Deleuze, Gilles, En medio de Spinoza, op. cit., pp. 491-493). Pero la lectura deleuziana toma otra deriva: «Más aún, ese ser común no es en Spinoza, como en Duns Scoto, un Ente neutralizado, indiferente el finito y al infinito, al in-se y al in-alio. Al contrario, es el Ente calificado de la substancia, en el que la substancia permanece en sí, pero también en el que los modos permanecen como en otra cosa. La inmanencia es pues la nueva figura que toma la teoría de la univocidad en Spinoza. El método sintético conduce necesariamente al planteamiento de este ser común o de esta causa inmanente» (Deleuze, Spinoza y el problema de la expresión, op. cit., p. 161). 
a lo real ${ }^{36}$. «La individuación para Spinoza no es ni cualitativa ni cuantitativa -en el sentido de la cantidad extensiva-. Es intensiva $»^{37}$. De ahí que vuelva a dirigir la mirada a nuestro autor escolástico. La noción del modus intrinsecus, en efecto y con la misma metáfora, es categoría ya desarrollada por Juan Duns Scoto ${ }^{38}$. Seguimos sin conocer si Spinoza leyó directamente a J. Duns Escoto, aunque si sabemos que pudo tener conocimiento de él por lecturas de terceros, comentarios de tertulia o círculo de amistades.

Así:

Duns Scoto decía que la cualidad, lo blanco, tiene una infinidad de modos intrínsecos... ¿Qué son los modus intrinsecus? Son las intensidades del blanco, una infinidad de intensidades luminosas. /...Pero hay otra cosa: una forma posee también una especie de como dicen en la Edad Media - latitud. Hay una latitud de la forma, tiene grados. Hay grados intensivos de la forma. Son las intensidades, son cantidades extensivas ${ }^{39}$.

Se apunta aquí, en el espinozismo, a relaciones de potencia, las potencias diferenciales de tal individuo concreto o tal otro, de Gilles, Baruj o Iohannis.

\section{Caja de herramientas}

En una entrevista-charla entre Michel Foucault y Gilles Deleuze, que, bajo el título de «Les intellectuels et le pouvoir», fue publicada en la revista L'Arc, núm. 49, 2ํำ trimes-

${ }^{36}$ Deleuze, En medio de Spinoza, op. cit., p. 393.

${ }^{37}$ Deleuze, En medio de Spinoza, op. cit., p. 328.

${ }^{38}$ Duns Escoto, Opus oxoniense [Ordinatio]. I, d3, q. 1 y 2, a. 4, n. 17: «Del concepto del ser infinito». Deleuze se fija en este pasaje de Juan Duns Escoto. Dice éste, en efecto, que la blancura tiene intensidades variables; que se agregan a ella como una cosa a otra, un signo sobre un libro; 'los grados de intensidad son determinaciones intrínsecas, modos intrínsecos de la blancura, que permanece unívocamente la misma, sea cual fuere la modalidad bajo la que se le considere' (reescribe el posmoderno: Deleuze, Spinoza y el problema de la expresión, op. cit., p. 189; y nota 14, donde se nos aclara, además, que la proximidadad entre ambos autores sólo alcanza en este punto a la cuestión de las cantidades intensivas o de los grados, siendo la teoría de la individuación entre ellos diferente. No nos indica cuánto. En todo caso, nos parece que sólo relativamente. En la nota 2 del Capítulo XII, «La esencia de modo: paso del infinito al finito» del último libro citado, Gilles Deleuze reconoce la deuda: «El problema de la intensidad o del grado desempeña un rol muy importante, especialmente en los siglos XIII y XIV: ¿una cualidad puede, sin cambiar de razón formal o de esencia, ser afectada por grados diversos? Y esas afecciones ¿pertenecen a la esencia misma, o solamente a la existencia? La teoría del modo intrínseco o del grado está particularmente desarrollada en el escotismo» (Deleuze, Spinoza y el problema de la expresión, op. cit., p. 185, n. 2). No hay eminencia: «Los modos son precisamente expresivos en tanto implican las mismas formas cualitativas que las que constituyen la esencia de la substancia» (Deleuze, Spinoza y el problema de la expresión, op. cit., p. 180). (Tercer grado de «expresión» en Spinoza).

${ }^{39}$ Deleuze, En medio de Spinoza, op. cit., pp. 404-405. 
tre, 1972, pp. 3-10, acuña este último, pero para referirse a la teoría en los tiempos contemporáneos del capitalismo avanzado y a los trabajos sobre microfísica del poder del primero, la exprexión «una caja de herramientas», en realidad metáfora o analogía:

Eso es, una teoría es exactamente como una caja de herramientas. Ninguna relación con el significante...Es preciso que sirva, que funcione. Y no para uno mismo. Si no hay personas para utilizarla, comenzando por el teórico mismo, que deja entonces de ser teórico, es que no vale nada, o que el momento no llegó aún. No se vuelve sobre una teoría, se hacen otras, hay que hacer otras ${ }^{40}$.

No es este tipo o sentido de caja de herramientas el que abordamos aquí. Sino en uno más primario o primitivo: se refiere tan sólo a un conjunto de categorías-instrumentos con los que G. Deleuze, como buen entomólogo o anatomista, escudriña el cuerpo filosófico de Baruj Spinoza, y todas ellas, una parte importante de ellas, al menos siete de ellas, tienen esta procedencia de la escolástica tardía o gótica. Sobra decir que, como reflejo de un espejo, esta intervención ayuda a configurar su propia cartografía filosófica, otro espacio, o cámara, al que se le puede aplicar la misma clave.

Para su desgracia, y contra su propósito, él mismo ha generado su propia escolástica, que, por lo general, carece de su clarividencia e incluso, sin exagerar, de la sutileza filosófica de su autor gótico de cabecera o referencia, Juan Duns Escoto.

Martin González Fernández martin.gonzalez@usc.es

Fecha de recepción: 23/09/2019

Fecha de aceptación: 03/12/2019

${ }^{40}$ En Foucault, M., Microfísica del poder. Edición y traducción de J. Varela y F. Álvarez-Uría, 2ª ed., Madrid, Ediciones La piqueta, 1980, p. 79. 